\title{
Publisher Correction: A selective peptide inhibitor of Frizzled 7 receptors disrupts intestinal stem cells
}

Aaron H. Nile, Felipe de Sousa e Melo, Susmith Mukund, Robert Piskol, Simon Hansen, Lijuan Zhou, Yingnan Zhang, Yue Fu, Emily B. Gogol, László G. Kömüves, Zora Modrusan, Stephane Angers D, Yvonne Franke, Christopher Koth, Wayne J. Fairbrother, Weiru Wang, Frederic J. de Sauvage and Rami N. Hannoush

Correction to Nature Chemical Biology https://doi.org/10.1038/s41589-018-0035-2, published online 9 April 2018.

The version of this article originally published contained older versions of the Life Sciences Reporting Summary and the Supplementary Text and Figures. The error has been corrected in the HTML and PDF versions of the article.

\section{Publisher Correction: Oxidative demethylation of algal carbohydrates by cytochrome P450 monooxygenases}

Lukas Reisky, Hanna C. Büchsenschütz, Jennifer Engel, Tao Song, Thomas Schweder, Jan-Hendrik Hehemann and

Uwe T. Bornscheuer

Correction to: Nature Chemical Biology https://doi.org/10.1038/s41589-018-0005-8

In the version of this article originally published, the line of conditions shown for NADH in Figure $2 \mathrm{~b}$ was shifted out of place. The error has been corrected in the HTML and PDF versions of the article.

Published online: 8 March 2018

https://doi.org/10.1038/s41589-018-0020-9

\section{Publisher Correction: Direct multiplex imaging and optogenetics of Rho GTPases enabled by near-infrared FRET}

Daria M. Shcherbakova, Natasha Cox Cammer, Tsipora M. Huisman, Vladislav V. Verkhusha and Louis Hodgson (D)

Correction to: Nature Chemical Biology https://doi.org/10.1038/s41589-018-0044-1, published online 23 April 2018

In the version of this article originally published, the values for time shown on the $x$ axis of Figure $5 \mathrm{c}$ were incorrect. The error has been corrected in all versions of the paper. 